\title{
Zinc and Folate Supplement Improves Semen Quality: A Prospective Study in Subfertile Males
}

\author{
Dr. Rolly Suriya Jahan ${ }^{1}$, Dr. Shakeela Ishrat ${ }^{2 *}$, Dr. Rupa Shamima Bashar ${ }^{3}$, Dr. Marufa Hossain ${ }^{4}$, Dr. Sumaiya Akter ${ }^{5}$, \\ Dr. Chalontika Rani ${ }^{6}$ \\ ${ }^{1}$ Dr. Rolly Suriya Jahan, Medical Officer, Department of Reproductive Endocrinology and Infertility, Bangabandhu Sheikh Mujib \\ Medical University, Dhaka, Bangladesh \\ ${ }^{2}$ Dr. Shakeela Ishrat, Associate Professor, Department of Reproductive Endocrinology and Infertility, Bangabandhu Sheikh Mujib \\ Medical University, Dhaka, Bangladesh \\ ${ }^{3}$ Dr. Rupa Shamima Bashar, Medical Officer, Department of Reproductive Endocrinology and Infertility, Bangabandhu Sheikh Mujib \\ Medical University, Dhaka, Bangladesh \\ ${ }^{4}$ Dr. Marufa Hossain, Medical Officer, Department of Reproductive Endocrinology and Infertility, Bangabandhu Sheikh Mujib \\ Medical University, Dhaka, Bangladesh \\ ${ }^{5}$ Dr. Sumaiya Akter, Consultant, Department of Reproductive Endocrinology and Infertility, Bangabandhu Sheikh Mujib Medical \\ University, Dhaka, Bangladesh \\ ${ }^{6}$ Dr. Chalontika Rani, Consultant, Department of Reproductive Endocrinology and Infertility, Bangabandhu Sheikh Mujib Medical \\ University, Dhaka, Bangladesh
}

\section{DOI: $10.36348 /$ sijog.2021.v04i04.010}

| Received: 09.03.2021 | Accepted: 10.04.2021 | Published: 21.04.2021

*Corresponding author: Dr. Shakeela Ishrat

\section{Abstract}

Background: The micronutrient folate and zinc has been associated with semen quality. Nutritional supplement with zinc and folate can help reverse some of the oxidative damage from environmental toxin and natural aging on spermatogenesis and sperm maturation. Till now there has been variable results in the research done on semen quality after folic acid and zinc sulfate supplementation. The objective of this study is to determine whether supplementation of folic acid and zinc sulfate has any beneficial effect on semen quality. Methods: This was a prospective, observational study carried out in the Department of Reproductive Endocrinology and Infertility, Bangabandhu Sheikh Mujib Medical University. Study participants are male partners of infertile couples, 70 in number, who attended the outpatient department and had abnormal semen parameters. Supplementation of folic acid and zinc sulfate was given to all male partners at a dose of $5 \mathrm{mg}$ tablet twice daily and $10 \mathrm{mg}$ tablet twice daily respectively for twelve weeks. Semen analysis was repeated after the period of three months supplementation of folic acid and zinc sulfate. Paired students $t$ tests were performed for test of significance. Results: Oligoasthenoteratozoospermia is most common (40\%) form of abnormality in semen parameter before supplementation. After supplementation $40 \%$ of report shows normozoospermia. Following supplementation of folic acid and zinc sulfate there was significant changes in sperm count $(\mathrm{P}<0.05)$, morphology $(\mathrm{P}<0.002)$, total motility $(\mathrm{P}<0.001)$. Regarding motility, all types of motility improved after supplementation including rapid-linear $(\mathrm{P}<0.001)$, slow linear $(\mathrm{P}<0.001)$, non-progressive $(\mathrm{P}<0.047)$. Number of immotile cell was reduced $(\mathrm{P}<0.001)$ after supplementation. Conclusion: An improvement in nutrition or supplementation with zinc and folate can have noticeable effects on semen quality and these may improve natural fertility and success rates with fertility treatment. Keywords: Zinc supplementation, Folic acid supplementation, male infertility, semen parameters.

Copyright $\odot 2021$ The Author(s): This is an open-access article distributed under the terms of the Creative Commons Attribution 4.0 International License (CC BY-NC 4.0) which permits unrestricted use, distribution, and reproduction in any medium for non-commercial use provided the original author and source are credited.

\section{INTRODUCTION}

Infertility is a common problem affecting one in six couples and male factor accounts for half of infertility [1]. The World Health Organization proposed a diagnostic classification of male infertility, based upon clinical assessment and the assessment of semen quality [2]. Male infertility is commonly due to qualitative and/or quantitative deficiency in the sperm $[3,4]$. More than $90 \%$ of male sub fertility is due to low sperm count, poor sperm quality or both, so semen 
Rolly Suriya Jahan et al; Sch Int J Obstet Gynec, Apr. 2021; 4(4): 136-142

quality is generally considered to be a proxy measure of male infertility [4].

The changes of semen quality can occur after exposure to toxic agents [5]. Human semen quality and fecundity have been declining during the last decades [6]. Environmental pollutants, occupational exposures and life style have been explored as possible contributors to those changes [9, 10]. A balanced nutritional diet and nutritional supplement with high antioxidant content can help reverse some of the oxidative damage from environmental toxin and natural aging.

Men with low sperm count may benefit from taking supplemental folic acid and zinc sulfate [9]. Dietary intake of antioxidants, such as vitamin $\mathrm{C}$ and $\mathrm{E}$, and B-carotin, and micronutrients, such as folate and zinc, have been demonstrated to be critically important for normal semen quality and reproductive function in a number of studies in both animals and humans [10]. There is substantial evidence of the role of micronutrients such as zinc, folic acid and antioxidant, in the maintenance of normal spermatogenesis and sperm maturation as well as in DNA metabolism, synthesis, repair and transcription [11].

The micronutrient folate and zinc has been associated with semen quality. Folate level in blood plasma and in seminal plasma have been positively associated with sperm concentration and count $[12,13]$. Folate deficiency has been shown to increase DNA strand breaks, DNA hypomethylation, chromosome instability and aneuploidy in lymphocytes [14-16]. Zinc levels in seminal plasma have been positively associated with sperm concentration and motility in some studies [17]. Zinc deficiency has been associated with increased DNA strand damage in sperm [18]. In clinical trial of men with round cell idiopathic syndrome, folinic acid supplementation (15mg / day) improved both sperm count and motility [19]. Sperm count also increased after combined zinc sulfate (66mg) and folic acid $(5 \mathrm{mg})$ treatment in a randomized clinical trial of sub fertile men, but not with either alone [9]. However in a trial where infertile men had a much higher dose of $500 \mathrm{mg} /$ day of zinc sulfate alone, there was a significant improvement of count and progressive motility [20].

Treatment of male infertility is a challenge to fertility specialists. Till now there has been variable results in the research done on semen quality after folic acid and zinc sulfate supplementation. This is another study to determine whether supplementation of folic acid and zinc sulfate has any beneficial effect on semen quality.

\section{METHOD}

This was a prospective, observational study carried out in the Department of Reproductive
Endocrinology and Infertility, Bangabandhu Sheikh Mujib Medical University. Study participants are male partners of infertile couples, 70 in number, who attended the outpatient department and had abnormal semen parameters. Exclusion criteria W3e33re azoospermia, varicocele and undescended testicle, history of hernia repair or vasectomy, history of chemotherapy or radiation treatments for any type of cancer, history of high rise of temperature in the previous three months.

The semen analysis was repeated after one month in case of any abnormal finding and the average of the two findings were taken as the semen parameters at baseline. The participant was counseled about the defect in semen parameters along with probable benefit of combined zinc sulfate and folic acid supplementation. Informed consent was taken. Supplementation of folic acid and zinc sulfate was given to all male partners at a dose of $5 \mathrm{mg}$ tablet twice daily and $10 \mathrm{mg}$ tablet twice daily respectively for twelve weeks. Communication with patients were maintained every fifteenth day over telephone, to ensure their compliance and acknowledgement.Semen analysis was repeated after the period of three months supplementation of folic acid and zinc sulfate.

\section{Semen Analysis}

The semen samples were produced by the participants via masturbation after an abstinence period of three days. These samples were collected in the Andrology Laboratory of BSMMU. After liquefaction, the semen parameters such as volume, sperm concentration, motility and morphology were determined. The sperm concentration was estimated by using the Makler Counting Chamber. Sperm morphology and motility was assessed under $\times 40$ objective lens. The semen parameter was interpreted as normal or abnormal according to the WHO (1999) semen analysis reference values.

The reference value for semen concentration was $\geq 20 \times 10^{6}$ sperm $/ \mathrm{ml}$, for motility $\geq 50 \%$ sperm with forward progression [ categories ' $a$ ' and ' $b$ '] or $\geq$ $25 \%$ sperm with category ' $a$ ' movement, and for morphology $\geq 14 \%$ sperm with normal morphology respectively. Oligozoospermia was determined when sperm concentration was less than the reference value. Likewise, asthenozoospermia was diagnosed when motility, and teratozoospermia when morphology, were below the reference values. An oligoteratozoospermia was diagnosed when all three variables (concentration, motility, morphology) were disturbed, combinations (oligoasthenozoospermia, oligoteratozoospermia, asthenoteratozoospermia) were used when two variables was disturbed.

\section{STATISTICAL ANALYSIS}

Data was processed and statistical analysis was performed by SPSS software 18. Paired students t tests 
Rolly Suriya Jahan et al; Sch Int J Obstet Gynec, Apr. 2021; 4(4): 136-142

were performed for test of significance. A value of < 0.05 was considered significant.

\section{RESULTS}

The baseline characteristics of the males are described in Table 1.Oligoasthenoteratozoospermia is most common (40\%) form of abnormality in semen parameter before supplementation. After supplementation $40 \%$ of report shows normozoospermia.
Following supplementation of folic acid and zinc sulfate there was significant changes in sperm count $(\mathrm{P}<0.05)$, morphology $(\mathrm{P}<0.002)$, total motility $(\mathrm{P}<0.001)$. Regarding motility, all types of motility improved after supplementation including rapid-linear $(\mathrm{P}<0.001)$, slow linear $(\mathrm{P}<0.001)$, non-progressive $(\mathrm{P}<0.047)$. Number of immotile cell was reduced $(\mathrm{P}<0.001)$ after supplementation.

Table-1: Baseline characteristics of the study participants $(n=70)$

\begin{tabular}{|l|l|l|}
\hline Parameters & Number of cases & Percentage of cases \\
\hline Age in years & 6 & \\
$20-25$ & 8 & 8.57 \\
$26-30$ & 28 & 11.4 \\
$31-35$ & 16 & 40 \\
$36-40$ & 12 & 22.8 \\
$>40$ & & 17.14 \\
\hline Economic status (Monthly income) & 6 & \\
Poor(< \$120) & 44 & 8.57 \\
Lower middle class(\$ 120-240) & 16 & 62.85 \\
Middle class(\$ 240-480) & 4 & 22.85 \\
Higher class(>\$480) & & 5.71 \\
\hline Type of infertility & 56 & \\
Primary & 14 & 80 \\
Secondary & & 20 \\
\hline Duration in years & 36 & \\
$1-5$ & 24 & 51.42 \\
$6-10$ & 8 & 34.28 \\
$11-15$ & 2 & 11.42 \\
$>15$ & & 2.85 \\
\hline Smoking habits & \\
Non-smoker & 46 & 34.28 \\
Smoker & & 65.71 \\
\hline
\end{tabular}

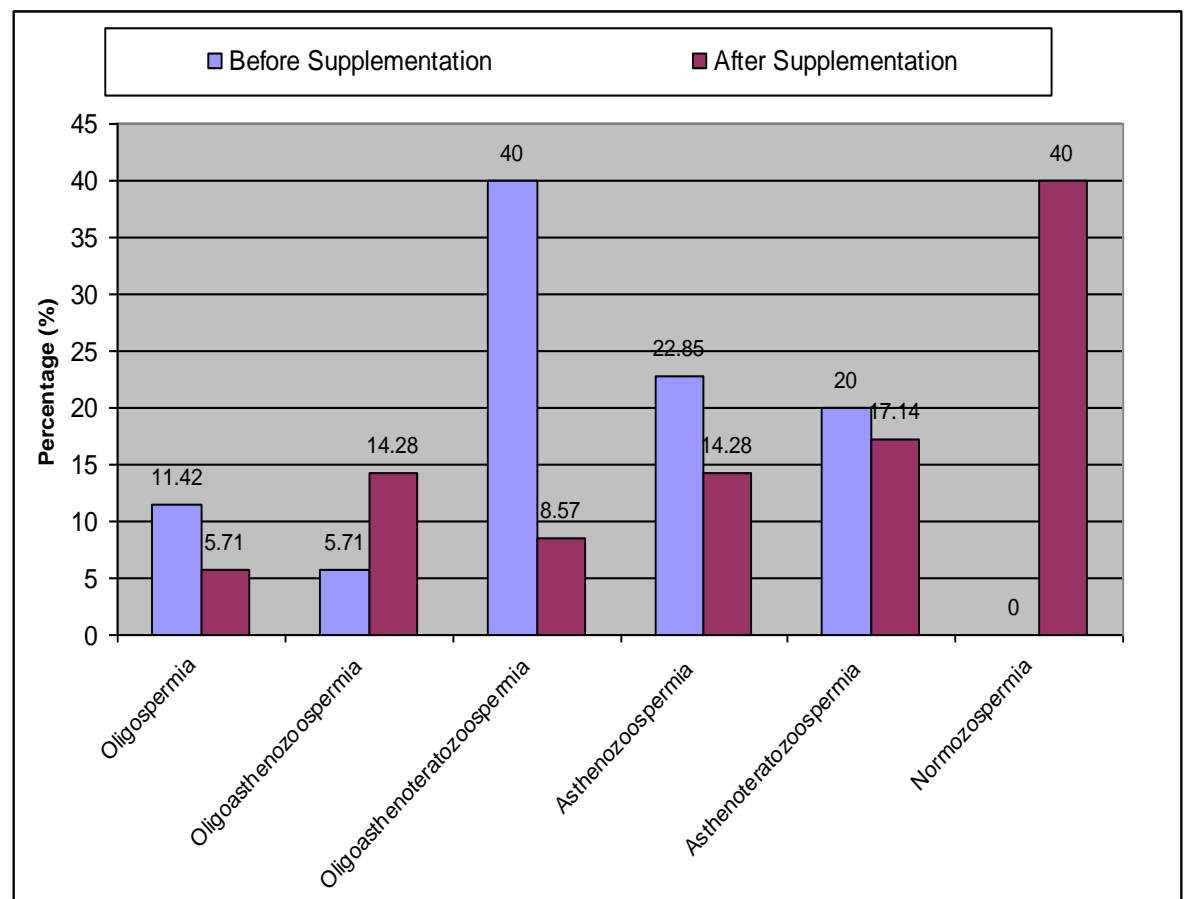

Fig-1: Type of semen abnormalities before and after supplementation 
Rolly Suriya Jahan et al; Sch Int J Obstet Gynec, Apr. 2021; 4(4): 136-142

Table-2: Pre supplement and Post supplement difference in sperm parameters of study participants $(\mathrm{n}=70)$

\begin{tabular}{|l|l|l|l|}
\hline Semen Parameters & $\begin{array}{l}\text { Pre supplement } \\
\text { Mean } \pm \text { SD }\end{array}$ & $\begin{array}{l}\text { Post supplement } \\
\text { Mean } \pm \text { SD }\end{array}$ & $\begin{array}{l}\text { Significance } \\
\text { p value }\end{array}$ \\
\hline Volume & $2.2000 \pm .86141$ & $2.3000 \pm .63929$ & 0.262 \\
\hline Count $($ million/ml) & $46.8857 \pm 78.38765$ & $63.2000 \pm 65.46104$ & 0.001 \\
\hline Morphology & $18.1714 \pm 14.21264$ & $26.8857 \pm 20.33028$ & 0.002 \\
\hline Motility & & & \\
Total motility & $34.5429 \pm 15.77256$ & $44.5714 \pm 20.40785$ & 0.001 \\
Rapid-linear & $11.9714 \pm 10.86274$ & $17.000 \pm 11.86885$ & 0.001 \\
Slow-linear & $10.8000 \pm 8.35724$ & $18.000 \pm 15.98006$ & 0.001 \\
Non-progressive & $12.8286 \pm 11.04795$ & $10.4286 \pm 8.19786$ & 0.047 \\
Immotile & $65.6000 \pm 17.35595$ & $55.1429 \pm 20.55342$ & 0.001 \\
\hline
\end{tabular}

\section{DISCUSSION}

This study was carried out among 70 cases with abnormal semen parameter in the Department of Reproductive Endocrinology \& Infertility, Dhaka. This place was selected because, this was the place where standard infertility treatment is carried out with low cost and patients from different corners of the country are being referred here. In this study it is noted that all semen parameters including count, motility, morphology improved significantly after folic acid $10 \mathrm{mg}$ and zinc sulfate $20 \mathrm{mg}$ daily supplementation for twelve weeks.

In this study majority of patient came from lower middle socioeconomic group about (62.85\%). This may be because treatment in this institution is low cost compared to other private facilities. Another implication of this finding is that the participants are economically disadvantaged so more likely to suffer from nutritional deficiency. In this study, we noted that most $(65.71 \%)$ of the male partners of infertile couple were smoker. which is supported by one study, which has reported an inverse dose response relationship between cigarette-years and sperm concentration [21].

Improvement in sperm count was observed after supplementation of folic acid and zinc but the improvement in total sperm count was not greater that the reference value of 20 million cells / $\mathrm{ml}$. Omu et al., [20] randomized 100 men with asthenozoospermia into two groups, one having $250 \mathrm{mg}$ zinc therapy for 3 months and the other no treatment. There was significant improvement in sperm count and progressive motility [20]. Tikkiwal et al [22] studied fourteen infertile males with idiopathic oligospermia after oral supplementation with $220 \mathrm{mg}$ zinc for 4 months. Seminal zinc increased significantly with significant improvement in sperm count, number of progressively motile and normal spermatozoa. One study reported that daily supplementation with $10 \mathrm{mg}$ folic acid for 30 days had no beneficial effect on sperm concentration in 40 normozoospermic and oligospermic men [23].

In this study oligoasthenoteratozoospermia is the most $(40 \%)$ common form of abnormality in semen parameter before supplementation. After supplementation it is noted that $40 \%$ of semen shows normozoospermia, with previous semen analysis showing some type of abnormality. This is supported by one study [24] which had significant improvement of sperm count and motility by administration of folic acid and zinc sulfate in infertile men.

Present study showed that change in volume is not significant in relation with treatment of folic acid and zinc sulfate. Volume of semen is an important parameter. Most men ejaculate 2.5-5 milliliters $(\mathrm{ml})$ of semen. Either significantly higher or lower amounts can be a sign of prostate problem, blockage, or retrograde ejaculation.

Total number of sperm count was improved after supplement of folic acid and zinc sulfate. Morphology was also improved after supplement. Regarding motility, total motility as well as rapidlinear, slow-linear and non-progressive motility increased after supplementation. This finding is similar that of double blind randomized, placebo controlled trial [25], carried over 26-weeks on 108 fertile and 103 infertile men. In this study both fertile and infertile group were assigned to receive one of four treatments: (1) zinc alone (15mg / day), (2) folic acid alone (5mg / day), (3) zinc plus folic acid, or (4) placebo. Sperm count, motility ( ability of sperm to move), and the shape of sperm cells, as well as blood level of folic acid and zinc were measured in both groups at the beginning and the conclusion of the study. According to the study, concentration of normal sperm cells increased in $74 \%$ of infertile men who took the combination of zinc and folic acid supplements, although many of these men failed to achieve normal sperm count values. The concentration of normal sperm cells were also increased in infertile men receiving zinc alone or folic acid alone. But these increases were not statistically significant. In those receiving placebo, the normal sperm count actually declined slightly. Fertile men had no significant change in sperm count, regardless of treatment. Motility and sperm cell shape were not affected by zinc and folic acid in either group. Level of folic acid increased in both fertile and infertile men who received supplemental folic acid, whereas zinc supplementation did not increase the average blood zinc 
Rolly Suriya Jahan et al; Sch Int J Obstet Gynec, Apr. 2021; 4(4): 136-142

concentration. Both nutrients are involved in DNA production, an important step in the formation of sperm cells. However, it is not clear to what extent subtle deficiencies of these nutrients contribute the common sperm abnormalities seen in infertile men. Further studies to clarify this are needed.

There was a study measuring zinc concentrations in the semen of infertile men. Those with low sperm count had higher zinc levels compared to men with azoospermia [26]. In a comparative study with fertile men, 60 infertile men with asthenozoospermia had higher peroxynitrite levels, NO synthase activity, and lower arginase activity in seminal plasma. The infertile men were treated with zinc sulfate $220 \mathrm{mg}$ cap, two capsule per day for 3 months. Volume of semen, progressive sperm motility percentage and total normal sperm count increased after zinc supplementation [27].

Zinc is an essential trace element which has critical role in various stages of spermatogenesis, ranging from the conversion of germ cells to sperm cells to activities in accessory sex glands. Zinc content in semen is 85-90 times higher than in blood, providing protection from oxidative damage [28].

A recent randomized controlled clinical trial including 2370 couples, used folic acid and zinc supplementation by male partners, compared to placebo. There was no significant improvements on semen quality measured after 6 months of randomization or in the couples live birth rates. The difference in their findings may be explained by different dietary habits and expected nutritional deficiency in the study participants [29].

A systematic review and meta-analysis of seven studies concluded that folate supplementation was more effective on sperm concentration than placebo but had little effect on sperm motiliy and morphology. Folate plus zinc supplementation showed higher effect on sperm concentration, morphology, but notonsperm motility. However the positive effect of folate plus zinc supplementation on sperm characteristics in sub fertile men should be interpreted with caution because of heterogeneity of the studies [30].

The cause of infertility is often treatable. Nutritional and life style changes increase chance of conception. In known cases avoidance of smoking, caffeine, drugs, alcohol consumption and stress, which are related to infertility, can improve fertility potential. Reproductive organ are highly susceptible to free radicals or oxidative damage from environmental toxicants like pesticides, insecticides, lead, radiation and heavy metals and natural aging. In oligozoospermia and asthenozoospermia where there is no specific reason for life style changes, a simple balanced diet and nutritional supplement with folic acid and zinc sulfate can help reverse some of the oxidative changes from environmental toxins and natural aging. Folic acid and zinc are critical nutrients in the male reproductive system for proper hormone metabolism, sperm formation and motility. An improvement in nutrition or supplementation is necessary to reverse damage to the reproductive system increased by the stress and postabuse.

From above discussion, we find that supplement of folic acid and zinc sulfate has beneficial effect on semen quality. In general, physiological doses of micronutrient have a better effect on absorption, transport and metabolic process, as long as no major disorders exist. It is apparent that an even larger beneficial effect may have been achieved if lower doses of folic acid and zinc sulfate is administered.

The limitation of our study are that we could not do the genetic testing and so could miss chromosomal defects if there was any. Few patients in this study did not response to treatment at all, genetic problem cannot be ignored in those cases. We did not measure pregnancy rates. Results would been more valid if the design was a case control study.

Male factor sub fertility is a multifactorial disorder. The findings of these study emphasize the importance of two micronutrients on spermatogenesis. Unlike genetic factors, nutritional factor factors can be changed by increasing intake. Whether the improvement in sperm concentration observed after administration of folic acid and zinc sulfate will lead to an increase in pregnancy rates remains to be established. Before wide-scale implementation of combined zinc and folic acid administration, we recommend that a larger randomized, placebocontrolled study on the efficacy and safety of these nutrient be done in our Bangladeshi population. Nevertheless, our findings suggest new avenues of future fertility research and treatment.

\section{CONCLUSION}

An improvement in nutrition or supplementation with zinc and folate can have noticeable effects on semen quality and these may improve natural fertility and success rates with fertility treatment.

\section{ACKNOWLEDGEMENT}

Our gratitude goes to the men who have been part of our study.

\section{DECLARATION \\ Funding: No funding sources}

Conflict of interest: None declared 
Rolly Suriya Jahan et al; Sch Int J Obstet Gynec, Apr. 2021; 4(4): 136-142

Ethical approval: The study was approved by the Institutional Ethics Committee

\section{REFERENCES}

1. Ferlin, A., \& Foresta, C. (2020). Infertility: practical clinical issues for routine investigation of the male partner. Journal of Clinical Medicine, 9(6), 1644.

2. Cooper, T. G., Noonan, E., Von Eckardstein, S., Auger, J., Baker, H. W., Behre, H. M., ... \& Vogelsong, K. M. (2010). World Health Organization reference values for human semen characteristics. Human reproduction update, 16(3), 231-245.

3. Irvine, D. S. (1998). Epidemiology and aetiology of male infertility. Human reproduction, 13(suppl_1), 33-44.

4. Hirsh, A. (2003). subfertility. Bmj, 327(7416), 669-672.

5. Wyrobek, A. J., Gordon, L. A., Burkhart, J. G., Francis, M. W., Kapp Jr, R. W., Letz, G., ... \& Whorton, M. D. (1983). An evaluation of human sperm as indicators of chemically induced alterations of spermatogenic function: a report of the US Environmental Protection Agency GeneTox Program. Mutation Research/Reviews in Genetic Toxicology, 115(1), 73-148.

6. Carlsen, E., Giwercman, A., Keiding, N., \& Skakkebæk, N. E. (1992). Evidence for decreasing quality of semen during past 50 years. British medical journal, 305(6854), 609-613.

7. Tielemans, E., Burdorf, A., te Velde, E. R., Weber, R. F., van Kooij, R. J., Veulemans, H., \& Heederik, D. J. (1999). Occupationally related exposures and reduced semen quality: a case-control study. Fertility and sterility, 71(4), 690-696.

8. Homan, G. F., Davies, M., \& Norman, R. (2007). The impact of lifestyle factors on reproductive performance in the general population and those undergoing infertility treatment: a review. Human reproduction update, 13(3), 209-223.

9. Wong, W. Y., Merkus, H. M., Thomas, C. M., Menkveld, R., Zielhuis, G. A., \& SteegersTheunissen, R. P. (2002). Effects of folic acid and zinc sulfate on male factor subfertility: a doubleblind, randomized, placebo-controlled trial. Fertility and sterility, 77(3), 491-498.

10. Ziegler, E. E., \& Filer L. J. (1996). Present knowledge in Nutrition. Washington, DC: ILSI Press.

11. Ebisch, I. M. W., Thomas, C. M. G., Peters, W. H. M., Braat, D. D. M., \& Steegers-Theunissen, R. P. M. (2007). The importance of folate, zinc and antioxidants in the pathogenesis and prevention of subfertility. Human reproduction update, 13(2), 163-174.

12. Wallock, L., Jacob, R., Woodall, A., \& Ames, B. (1997, February). Nutritional status and positive relation of plasma folate to fertility indices in nonsmoking men. In FASEB JOURNAL (Vol. 11,
No. 3, pp. 1068-1068). 9650 ROCKVILLE PIKE, BETHESDA, MD 20814-3998 USA: FEDERATION AMER SOC EXP BIOL.

13. Wallock, L. M., Tamura, T., Mayr, C. A., Johnston, K. E., Ames, B. N., \& Jacob, R. A. (2001). Low seminal plasma folate concentrations are associated with low sperm density and count in male smokers and nonsmokers. Fertility and sterility, 75(2), 252259.

14. Pogribny, I. P., Basnakian, A. G., Miller, B. J., Lopatina, N. G., Poirier, L. A., \& James, S. J. (1995). Breaks in genomic DNA and within the p53 gene are associated with hypomethylation in livers of folate/methyl-deficient rats. Cancer research, 55(9), 1894-1901.

15. Pogribny, I. P., Muskhelishvili, L., Miller, B. J., \& James, S. J. (1997). Presence and consequence of uracil in preneoplastic DNA from folate/methyldeficient rats. Carcinogenesis, 18(11), 2071-2076.

16. Wang, X. U., Thomas, P., Xue, J., \& Fenech, M. (2004). Folate deficiency induces aneuploidy in human lymphocytes in vitro-evidence using cytokinesis-blocked cells and probes specific for chromosomes 17 and 21. Mutation Research/Fundamental and Molecular Mechanisms of Mutagenesis, 551(1-2), 167-180.

17. Chia, S. E., Ong, C. N., Chua, L. H., Ho, L. M., \& Tay, S. K. (2000). Comparison of zinc concentrations in blood and seminal plasma and the various sperm parameters between fertile and infertile men. Journal of andrology, 21(1), 53-57.

18. Kerns, K., Zigo, M., \& Sutovsky, P. (2018). Zinc: A necessary ion for mammalian sperm fertilization competency. International journal of molecular sciences, 19(12), 4097.

19. Bentivoglio, G., Melica, F., \& Cristoforoni, P. (1993). Folinic acid in the treatment of human male infertility. Fertility and sterility, 60(4), 698-701.

20. Omu, A. E., Dashti, H., \& Al-Othman, S. (1998). Treatment of asthenozoospermia with zinc sulphate: andrological, immunological and obstetric outcome. European Journal of Obstetrics \& Gynecology and Reproductive Biology, 79(2), 179-184.

21. Chia, S. E., Ong, C. N., \& Tsakok, F. M. H. (1994). Effects of cigarette smoking on human semen quality. Archives of andrology, 33(3), 163-168.

22. Tikkiwal, M., Ajmera, R. L., \& Mathur, N. K. (1987). Effect of zinc administration on seminal zinc and fertility of oligospermic males. Indian journal of physiology and pharmacology, 31(1), 30-34.

23. Landau, B., Singer, R., Klein, T., \& Segenreich, E. (1978). Folic acid levels in blood and seminal plasma of normo-and oligospermic patients prior and following folic acid treatment. Experientia, 34(10), 1301-1302.

24. Ebisch, I. M. W., Pierik, F. H., De Jong, F. H., Thomas, C. M. G., \& Steegers Theunissen, R. P. M. (2006). Does folic acid and zinc sulphate 
intervention affect endocrine parameters and sperm characteristics in men?. International journal of andrology, 29(2), 339-345.

25. Okon, K. O., Nwaogwu, M., Zailani, S. O., \& Chama, C. (2005). Pattern Of Seminal Fluid Indices Among Infertile Male Partners Attending The Infertility Clinic Of University Of Maiduguri Teaching Hospital, Maiduguri Nigeria. Highland Medical Research Journal, 3(1), 18-23.

26. Milostić-Srb, A., Včev, A., Tandara, M., Marić, S., Kuić-Vadlja, V., Srb, N., \& Holik, D. (2020). Importance of Zinc Concentration in Seminal Fluid of Men Diagnosed with Infertility. Acta Clinica Croatica, 59(1), 154-160.

27. Hadwan, M. H., Almashhedy, L. A., \& Alsalman, A. R. S. (2014). Study of the effects of oral zinc supplementation on peroxynitrite levels, arginase activity and NO synthase activity in seminal plasma of Iraqi asthenospermic patients. Reproductive Biology and Endocrinology, 12(1), 1-8.
28. Vickram, S., Rohini, K., Srinivasan, S., Nancy Veenakumari, D., Archana, K., Anbarasu, K., ... \& Srikumar, P. S. (2021). Role of Zinc (Zn) in Human Reproduction: A Journey from Initial Spermatogenesis to Childbirth. International Journal of Molecular Sciences, 22(4), 2188.

29. Schisterman, E. F., Sjaarda, L. A., Clemons, T., Carrell, D. T., Perkins, N. J., Johnstone, E., ... \& Mumford, S. L. (2020). Effect of folic acid and zinc supplementation in men on semen quality and live birth among couples undergoing infertility treatment: a randomized clinical trial. Jama, 323(1), 35-48.

30. Irani, M., Amirian, M., Sadeghi, R., Le Lez, J., \& Roudsari, R. L. (2017). The effect of folate and folate plus zinc supplementation on endocrine parameters and sperm characteristics in sub-fertile men: a systematic review and metaanalysis. Urology journal, 14(5), 4069-4078. 